\title{
Possible Treatment of Lung Failure in COVID 19 Patients
}

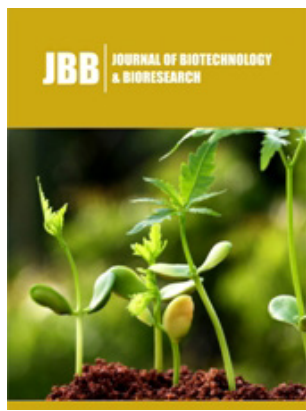

*Corresponding author: Charles $\mathrm{H}$ Williams, The Williams research laboratory, Sunrise Beach, USA

Submission: 梅 October 27, 2020

Published: 监 November13, 2020

Volume 2 - Issue 4

How to cite this article: Charles $\mathrm{H}$ Williams. Possible Treatment of Lung Failure in COVID 19 Patients. J Biotech Biores. 2(4). JBB.000543.2020.

Copyright@ Charles H Williams, This article is distributed under the terms of the Creative Commons Attribution 4.0 International License, which permits unrestricted use and redistribution provided that the original author and source are credited.

\author{
Charles H Williams ${ }^{1 *}$ \\ ${ }^{1}$ The Williams research laboratory, USA
}

\section{Opinion}

The development of lung failure is a severe complication of COVID 19. My friend Bill Bruns, St Clair, MO died recently even though he was on a ventilator and in an induced coma at the Washington, MO Hospital. His wife also had COVID 19, but did not develop the acute lung failure aspect, so she quarantined at home and fully recovered [1,2]. Two of my immediate family members contracted COVID 19 but did not develop the acute lung failure aspect and quarantined at home and fully recovered. They went back to work at the ear, nose, and throat clinic where they had contracted the disease.

The production of ventilators was ramped up to supply the demand necessitated by COVID 19 patients. However, the mechanical ventilation of patients does not solve the problem of getting oxygen into the red blood cells if the lung arterioles are plugged by micro clots that shut down the flow of blood thru the lung capillaries for exchange of lung gasses.

This sounds like the lung failure that we researched extensively in pigs while working at TTUHSC-El Paso.

We assumed that the red blood cells were forming small clumps of two or more RBC which then plugged the capillaries in the lung since only single RBC can pass through the capillaries in single file to exchange blood gases and oxygenate the patient.

We treated the clumping problem with ABOKINASE or STREPTOKINASE, thereby dissolving the clumps and restoring blood flow through the capillaries which restored oxygenation to the patient. Our first patient, who had fallen from his roof, in this experimental protocol pinked up as they were infusing the ABOKINASE via the pulmonary artery catheter. The blood gas analysis confirmed the improvement in lung function. The treatment lasted for 24 hours, then he started to go down again. A second treatment was infused and he again recovered and was doing well for 3 to 4 days [3,4]. A third treatment was infused and the patient fully recovered lung function and walked out of the hospital after 58 days and went into physical rehab.

There is a common lung failure problem from traumatic shock, septic shock, or gunfire shock that ties these lung failure problems together. That is the development of micro clots that plug the capillaries in the lung.

This same treatment may need to be used in treating lung failure in COVID 19 patients that are experiencing lung failure. The USA has recorded over 200,000 COVID 19 deaths. These deeaths appear to be lung failure problems as ventilators have been readily available at all hospitals. 


\section{References}

1. Hardaway RM, Williams CH, Sun Y (1996) A new approach to the treatment of experimental septic shock. Journal of Surgical Research 61(2): 311-316.

2. Hardaway RM, Williams CH, Vasquez Y (2001) Disseminated intravascular coagulation in sepsis. Semin Thromb Hemost 27(6): 577583.
3. Hardaway RM (2009) One surgeon's army experience with wound shock from pearl harbor to the present. Mil Med 174(9): 944-947.

4. Hardaway RM (2006) A brief overview of acute respiratory distress syndrome. World J Surg 30(10): 1829-1834.

For possible submissions Click below: 